\title{
Evaluation of Red Light Camera Enforcement at Signalized Intersections
}

\author{
Abdulrahman AlJanahi \\ Department of Civil and Architectural Engineering, \\ Director, Centre for Transport and Road Studies (CTRS), College of Engineering, University of Bahrain, P.O. Box. 32038 - Isa \\ Town, Kingdom of Bahrain
}

Received 25 May 2005; accepted 9 May 2006

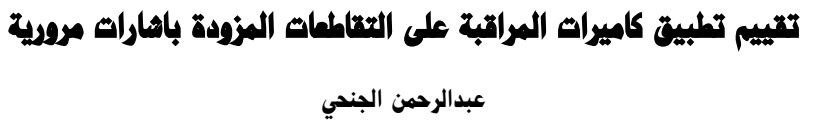

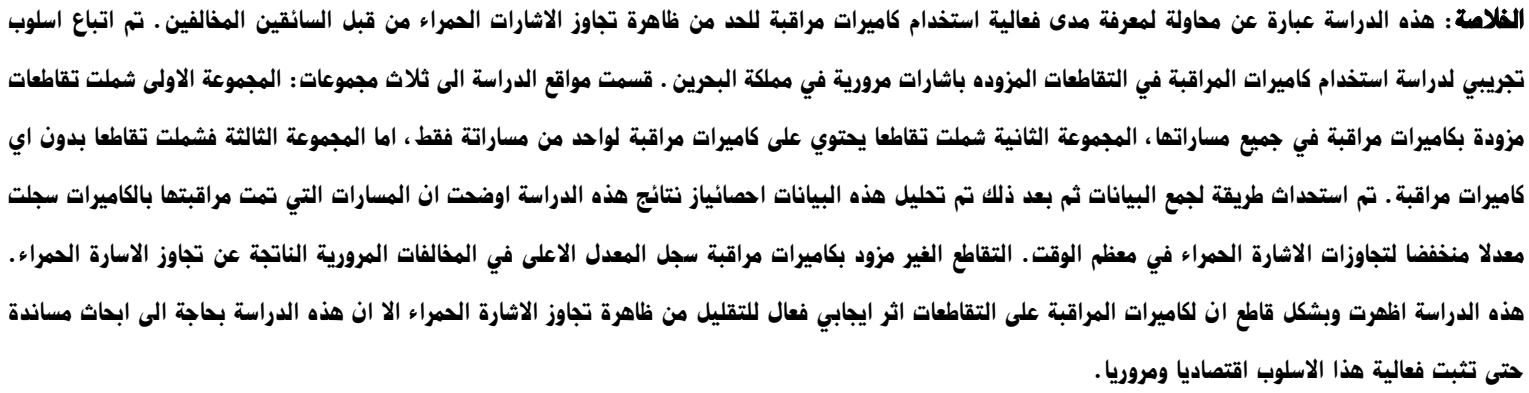

الهنزهات الهنتامية: كاميرات الاشارة الحمراء،مزود باشارات مرور، تقاطع، مواصلات، مخالفة، حادث.

\begin{abstract}
The study attempts to find the effectiveness of adopting red light cameras in reducing red light violators. An experimental approach was adopted to investigate the use of red light cameras at signalized intersections in the Kingdom of Bahrain. The study locations were divided into three groups. The first group was related to the approaches monitored with red light cameras. The second group was related to approaches without red light cameras, but located within an intersection that had one of its approaches monitored with red light cameras. The third group was related to intersection approaches located at intersection without red light cameras (controlled sites). A methodology was developed for data collection. The data were then tested statistically by Z-test using proportion methods to compare the proportion of red light violations occurring at different sites. The study found that the proportion of red light violators at approaches monitored with red light cameras was significantly less than those at the controlled sites for most of the time. Approaches without red light cameras located within intersections having red light cameras showed, in general, fewer violations than controlled sites, but the results were not significant for all times of the day. The study reveals that red light cameras have a positive effect on reducing red light violations. However, these conclusions need further evaluations to justify their safe and economic use.
\end{abstract}

Keywords: Red light cameras, Signalized, Intersection, Transportation, Violation, Accident

\section{Background}

It is a well known belief that the traffic system depends on three elements: engineering, enforcement, and education. These three elements have been developed very much during the few last decades. This paper discusses the elements of traffic enforcement, in particular, the development of a relatively new technique, in this part of the world, using cameras at signalized intersections to snap red light phase violators (it will be referred to as "red light camera" in this paper).

$\overline{\text { * Corresponding author's e-mail: aaljanahi@eng.uob.bh }}$
As the red light camera is a relatively new technique in the region, there have been lots of discussions and debates about its efficiency in reducing the number of the red light violators. Looking into the experiences of other countries might give a more comprehensive view. The red light camera was found to be very effective in Virginia, USA (Ruby and Hobeika, 2003). The violation rates were reduced by $36 \%$ during the first three months of installation, and even, improved to $69 \%$ after six months of camera operation. Another encouraging result was reported from California, USA (Retting et al. 1999). a). The red light violation rates were reduced by approximately $42 \%$. The other good revelation was that even at the non- 
equipped intersections with red light cameras, the violations reduced. Another study (Retting, et al. 1999 b) supported those findings, which reported that after installing red light cameras in Fairfax, Virginia, U.S.A, the situation showed a significant reduction in red light violations after one year of installation. Again in San Francisco, California it was reported that the red light violators dropped by $40 \%$ after 6 months of installing the red light cameras (Fleck and Smith, 1999). Similar results were found in the United Kingdom (Harbord and Jones, 1996). The automatic detection by red light running cameras was found to be useful on Motorway M 25.

On the other hand Kea, et al. (2002) were more conservative in advocating the use of new technologies as the experiment was still new and needed more time to be evaluated. Some other reports even went further to present conflicting results for red light violators after installing red light cameras. The before-and-after study by Schattler, et al. (2003) showed mixed results, as no significant differences were found in the violation rates. Miller (2003) found that the yellow change interval might have an effect on red light violations. Other researchers indicated that to gain better results in cutting down the number of red light violators, education should be combined with the use of automated detectors. For example, Tanawneh, et al. (1999), found that combining enforcement with education did have an impact in reducing the number of red light violations. Others (Blakey, 2003) determined that traffic engineers should play a vital role in selecting red light camera sites to ensure best results. This experience was supported by the case of San Francisco (Fleck and Smith, 1999) where installing red light cameras included the interaction of engineering, enforcement, educational and legislation affairs in producing an integrated system.

As was observed in some studies, the legal side of using red light cameras should be thoroughly considered. For example a red light violation camera system is still not legalized in many parts of USA (Datta, et al. 2000). This opinion is echoed by Lawson, et al. (1992), who advised that the operators should be aware in developing policies so as to go hand-in-hand with the legal aspects and recommended further areas of research. Some researchers (Wissinger, et al. 2000) in this field have been trying to explore the public acceptance of this technique. They found that there were divisions in the public opinion at taking extremes. One group of public was asking for a grace period for violators while the other extreme group was asking for a zero-tolerance for the violators. Almost all the opinions were supporting an automated enforcement. According to Retting, et al. (1999), the public support reached $80 \%$ for this automated enforcement. Another study which was conducted in U.K showed that public support was weak for a similar device, namely a speed radar, as it was perceived as a tool to collect revenues for the local agency (Keenan, 2001). The same study emphasized the proper site selection for the device as an important condition for increasing its effectiveness.
Regardless of public opinion, it is important to use the new technologies in traffic enforcement (Magee, 1999; Chen, et al. 2000). Other benefits of red light cameras were experimented. Red light cameras have been successfully used in data collection to assist the feasibility of installing such systems (Banghman, 2002). It seems that red light violators can be grouped according to certain characteristics. It was found that drivers who were young, less likely to wear seat belts, have poorer driving records, and drove smaller and older vehicles were more likely to violate red light than other drivers (Retting and Williams, 1996).

Also, it seems that drivers tend to violate red light if they were alone compared to a situation where they were accompanied by other passengers (Ponter and Derry, 2001). The other results were that one of each five drivers violated red light; younger drivers tend to violate more than older drivers; and being in hurry not in stress, and were reason number one for violating. Among the population surveyed, only $6 \%$ were caught and punished. Only one out of ten respondents was exposed to a crash due to running red lights.

\section{Introduction}

Traffic signals were first introduced in 1868 in the UK, in a primitive way and it was re-introduced in New York, USA in 1918 to regulate traffic flow (Salter, 1988). They proved to enhance the flow of traffic at intersections. New generations of traffic signals were introduced with a computer processing power to give better performance and more functions. Traffic signal effectiveness depends mainly on the road users, especially the drivers observing these signals. The majority of the drivers do observe, but unfortunately, a minority violates these signals. The accident severity of such violations is high (Fleck and Smith, 1999).

The enforcement camera at signalized intersections works on the following basic principle: when the sensors (ie. loops under the surface of the road) detect the movement of a vehicle during the red-phase of that approach, the enforcement camera is activated and photographic /digital shots are taken. The focus of the red light will be on the plate number of the vehicles (Ruby and Hobeika, 2003).

\section{Objective}

The objective of this paper is to measure the effect of red light camera enforcement on the number of red light violators at signalized intersections. The effect was measured for different intersection approaches monitored with and without red light cameras.

\section{Methodology}

To fulfill the objective of the study, the following methodology was applied: 


\subsection{The Hypothesis}

The first hypothesis was that the presence of red light cameras at an approach located at signalized intersection would lower the number of red light violators compared to approaches monitored without red light cameras, depending on the direct and continuous enforcement provided by red light cameras.

The second hypothesis was that an approach without a red light camera located within a signalized intersection with a red light camera at other approaches would have less red light violators than an approach located at a signalized intersection without using a red light camera at all, depending on the indirect enforcement effect.

\subsection{Selection of the Sites}

A number of signalized intersections were chosen. The selected sites have similar geometric, traffic, and environmental conditions. Figs. 1, 2, 3, and 4 illustrate plans of the sites. The sites were divided into three categories according to the hypothesis:

- Type I (R/D and G/D: approaches located at signalized intersections with red light cameras installed. They are called "direct-effect" sites.

- Type II (R/ID and G/ID: approaches with no red light cameras, however; but located at signalized intersections that have red light cameras at another approach. They are called "indirect-effect" sites.

- Type III (S/N and J/N): Approaches with no red light camera located at signalized intersections. They are called "no-effect" (controlled) sites.

Number of violators at direct-effect sites (Type I) was compared to no-effect sites (Type III). The results would test the first hypothesis. Another comparison to the second hypothesis would be conducted to compare the number of violators at indirect-effect sites (Type II) with no effect sites (Type III).

\subsection{Observations}

\subsubsection{Observation Times}

The observations were carried out for half an hour during the morning peak (ie. 7:00 - 8:00), outside morning peak, during evening peak (14:00 - 15:00), and during night time (ie. 21:00 - 22:00). Each observation was repeated three times on three different working days. The observation outcomes were combined to represent each interval. At G/D and intersection no observations were taken during night time due to external factors beyond the investigator's control (no observation was allowed for direct effect approach at that site during night due to security reasons).

\subsubsection{Data Collected}

Total number of vehicles that passed through each phase during each time interval were recorded, Tables 16. All lanes, straight and left turning, were considered in the analysis as the objective of this study concentrated on red light violations. Further studies may test the effect of different lane orientation on red light violation. The proportion of red light violators as a percent of the total traffic entering the intersection at the studied approach was calculated as the number of red light violators was divided over the total number of vehicles passing through the intersection expressed as a percentage. The results are presented in Tables 1 to 6 . However, Fig. 5 summarizes the percent of violators for all the evaluated sites. Violating vehicles were defined as vehicles crossing the stopping white line at the start of the red light. All vehicles crossing the stopping white line during yellow-light were recorded even though they were not considered as violators according to the local regulations. One member of the team was responsible for observing the change of lights during the phase.

\subsubsection{Conditions of Observations}

The observers were instructed to take positions far enough from the traffic so that the drivers would not be distracted by them. The observers were supplied by ready-made log sheets for data entry at each site. The tasks were distributed randomly among the observers to ensure smooth operation. The log sheet was checked in the office to ensure its accuracy. Finally, the data were entered to the computer using pre-designed Excel Sheets.

\section{Analysis}

\subsection{Variable Determination}

For each site, number of red light violators in each interval was converted to proportions (Section 4.3.2).

\subsection{Statistical Test}

Z-test was used (Bluman, 1992) to compare the differences statistically, if any, between the studied sites. In this case the comparison was not between absolute numbers but between percentages (i.e. percentage of drivers violating the red light), so Z-test for comparing two proportions was used. The normal approximation to the binomial is applied to each population, so that the estimators of the population $p_{1}{ }^{\wedge}$ and $p_{2}{ }^{\wedge}$ had approximately normal distribution with two conditions to be fulfilled:

1. The samples must be independent of each other which was the case here; and

2. np and nq must be 5 or more which was the case as well (the sample size $n$ is more than 30 ).

The formula used was:

$$
Z=\frac{\left(p_{1}^{\wedge}-p_{2}^{\wedge}\right)-\left(p_{1}-p_{2}\right)}{\sqrt{p q}\left(\frac{1}{n_{1}}+\frac{1}{n_{2}}\right)}
$$




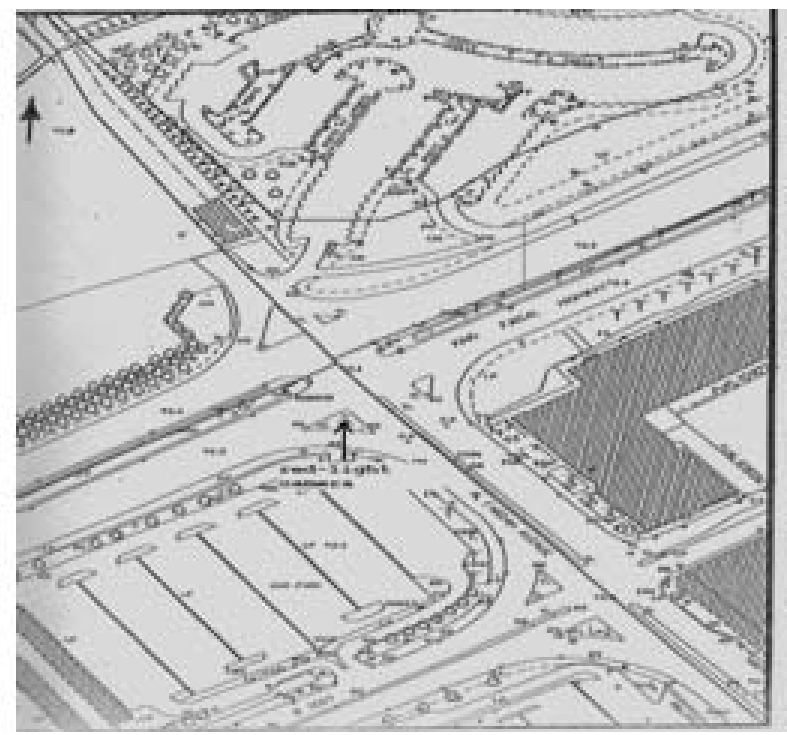

Figure 1. A plan for $\mathrm{R} / \mathrm{D}$ and $\mathrm{R} / \mathrm{ID}$ site

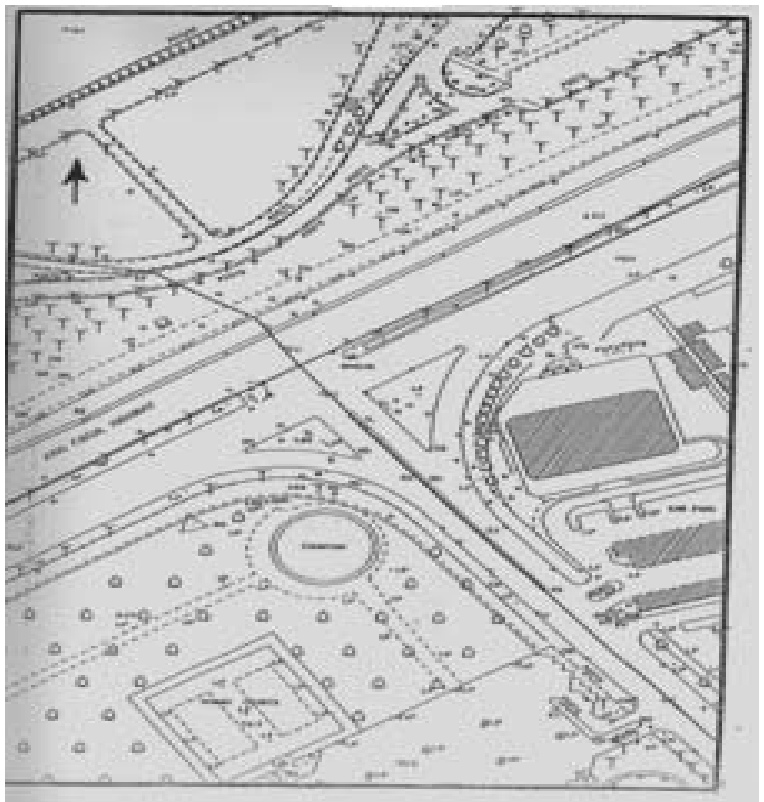

Figure 3. A plan for $\mathrm{S} / \mathrm{N}$ site

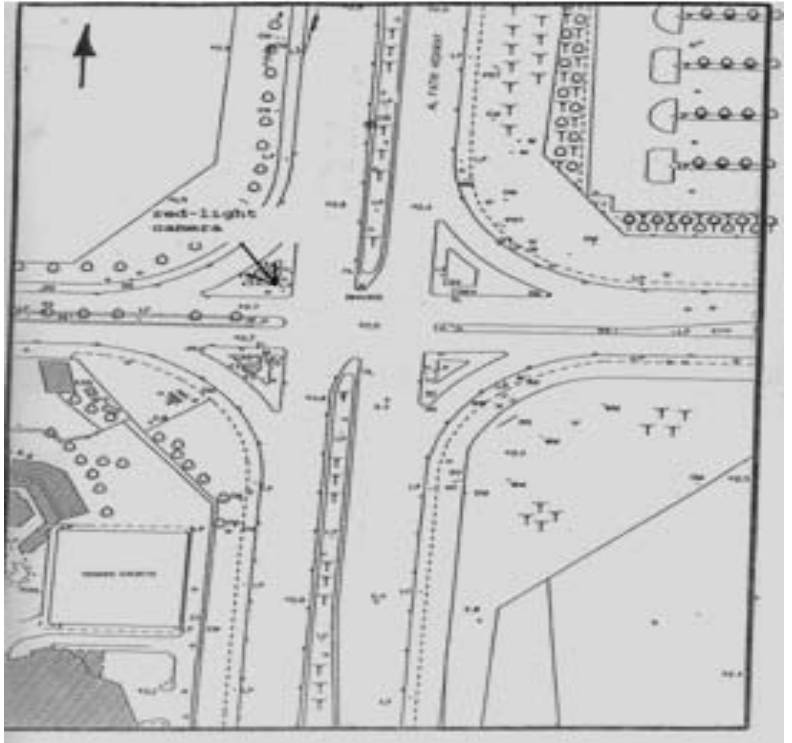

Figure 2. A plan for G/D and G/ID site

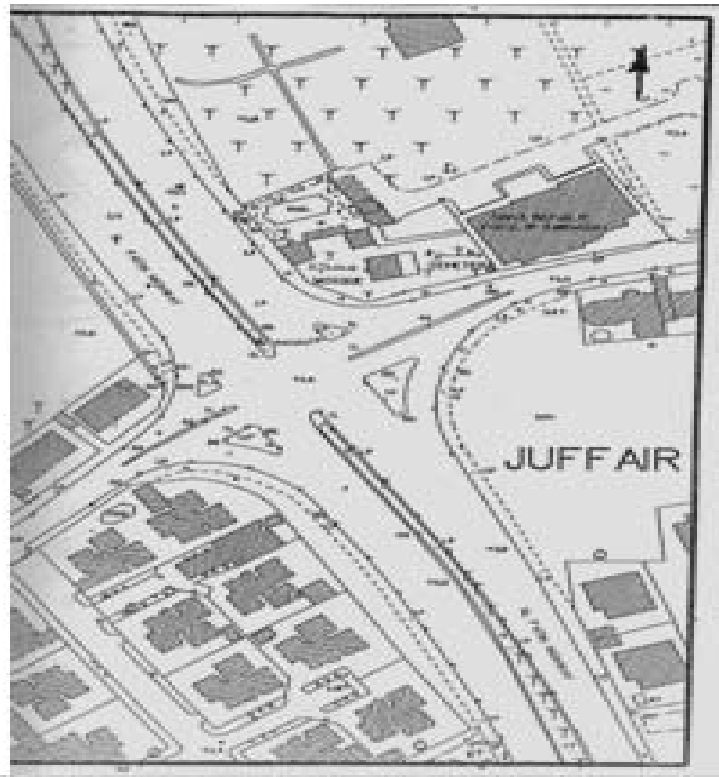

Figure 4. A plan for $\mathrm{J} / \mathrm{N}$ site

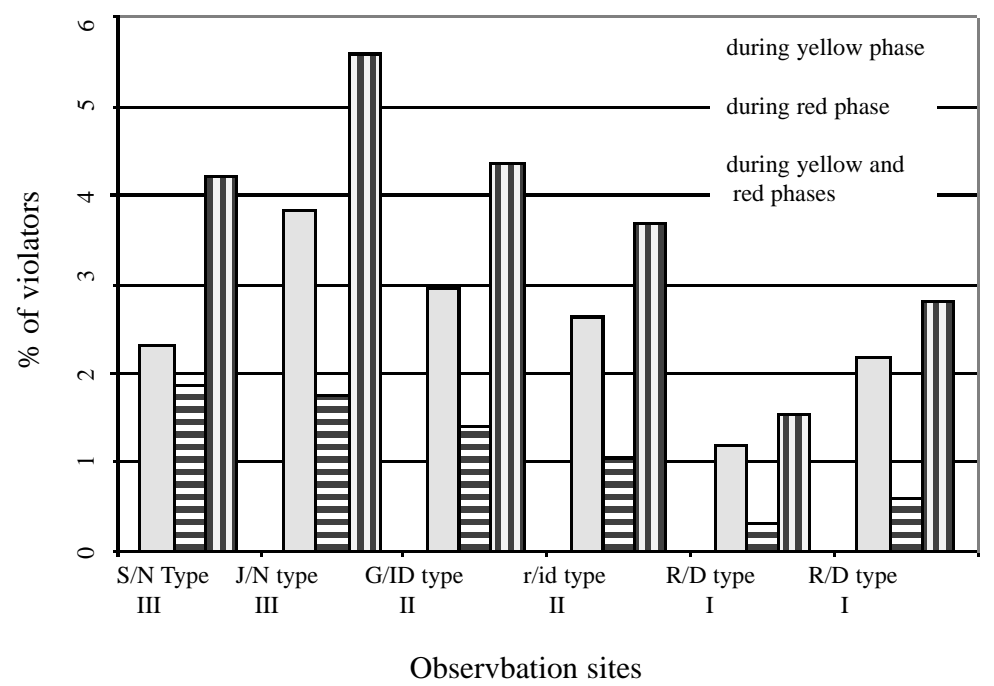

Figure 5. Proportion of red light violators to total traffic passing through the evaluated approachs for all sites 
The Journal of Engineering Research Vol. 4, No.1 (2007) 37-47

Table 1. Total number of vehicles passing during different traffic signal times at R/D signlized intersection (Type I)

$\begin{array}{lccccc}\text { Signal Time } & \begin{array}{c}\text { Morning } \\ \text { Peak }\end{array} & \begin{array}{c}\text { Morning Off- } \\ \text { peak }\end{array} & \begin{array}{c}\text { Afternoon } \\ \text { Peak }\end{array} & \begin{array}{c}\text { Night } \\ \text { Time }\end{array} & \text { Total Vehicles } \\ \text { Green Time } & 1536 & 558 & 1068 & 698 & 3860 \\ \text { Yellow } & 13 & 10 & 7 & 17 & 47 \\ \text { Time } & 5 & 3 & 1 & 4 & 13 \\ \text { Red Time } & 1554 & 571 & 1076 & 719 & 3920 \\ \text { Total Veh. } & & & \end{array}$

Table 2. Total number of vehicles passing during different traffic signal times at R/ID intersection (Type II)

$\begin{array}{lccccc}\text { Signal Time } & \begin{array}{c}\text { Morning } \\ \text { Peak }\end{array} & \begin{array}{c}\text { Morning Off- } \\ \text { peak }\end{array} & \begin{array}{c}\text { Afternoon } \\ \text { Peak }\end{array} & \begin{array}{c}\text { Night } \\ \text { Time }\end{array} & \text { Total Vehicles } \\ \text { Green Time } & 1309 & 509 & 555 & 516 & 2889 \\ \text { Yellow Time } & 24 & 25 & 15 & 15 & 79 \\ \text { Red Time } & 9 & 11 & 5 & 7 & 32 \\ \text { Total Veh. } & 1342 & 545 & 575 & 538 & 3000\end{array}$

Table 3. Total number of vehicles passing during different traffic signal times at G/D signalized intersection (Type I)

\begin{tabular}{lccccc}
\multicolumn{1}{c}{ Phase } & $\begin{array}{c}\text { Morning } \\
\text { Peak }\end{array}$ & $\begin{array}{c}\text { Morning Off- } \\
\text { peak }\end{array}$ & $\begin{array}{c}\text { Afternoon } \\
\text { Peak }\end{array}$ & $\begin{array}{c}\text { Night } \\
\text { Time }\end{array}$ & Total Vehicles \\
Green Time & 1066 & 506 & 517 & N/A & 2089 \\
Yellow Time & 7 & 21 & 19 & N/A & 47 \\
Red Time & 1 & 8 & 4 & N/A & 13 \\
Total Veh. & 1074 & 535 & 540 & N/A & 2149
\end{tabular}

* N/A: Not applicable

Table 4. Total number of vehicles passing during different traffic signal times at G/ID signalized intersection (Type II)

$\begin{array}{lccccc}\text { Signal Time } & \begin{array}{c}\text { Morning } \\ \text { Peak }\end{array} & \begin{array}{c}\text { Morning Off- } \\ \text { peak }\end{array} & \begin{array}{c}\text { Afternoon } \\ \text { Peak }\end{array} & \begin{array}{c}\text { Night } \\ \text { Time }\end{array} & \text { Total Vehicles } \\ \text { Green Time } & 949 & 588 & 688 & 293 & 2518 \\ \text { Yellow Time } & 31 & 26 & 18 & 3 & 78 \\ \text { Red Time } & 8 & 5 & 13 & 11 & 37 \\ \text { Total Veh. } & 988 & 619 & 719 & 307 & 2633\end{array}$

Table 5. Total number of vehicles passing during different traffic signal times at $\mathrm{S} / \mathrm{N}$ signalized intersection (Type III)

$\begin{array}{lccccc}\text { Signal Time } & \begin{array}{c}\text { Morning } \\ \text { Peak }\end{array} & \begin{array}{c}\text { Morning Off- } \\ \text { peak }\end{array} & \begin{array}{c}\text { Afternoon } \\ \text { Peak }\end{array} & \begin{array}{c}\text { Night } \\ \text { Time }\end{array} & \text { Total Vehicles } \\ \text { Green Time } & 358 & 334 & 333 & 455 & 1480 \\ \text { Yellow Time } & 9 & 8 & 11 & 8 & 36 \\ \text { Red Time } & 13 & 6 & 5 & 5 & 29 \\ \text { Total Veh. } & 380 & 348 & 349 & 468 & 1545\end{array}$

Table 6. Total number of vehicles passing during different traffic signal times at $\mathbf{J} / \mathrm{N}$ signalized intersection (Type III)

\begin{tabular}{lccccc}
\multicolumn{1}{c}{ Phase } & $\begin{array}{c}\text { Morning } \\
\text { peak }\end{array}$ & $\begin{array}{c}\text { Morning off- } \\
\text { peak }\end{array}$ & Afternoon peak & $\begin{array}{c}\text { Night } \\
\text { time }\end{array}$ & Total \\
Green & 849 & 583 & 548 & 282 & 2262 \\
Yellow & 40 & 25 & 16 & 11 & 92 \\
Red & 21 & 12 & 3 & 6 & 42 \\
Total & 910 & 620 & 567 & 299 & 2396
\end{tabular}


where:

$Z=$ test value

$p_{1}{ }^{\wedge}=$ sample proportion used to estimate the first population proportion

$p_{2}{ }^{\wedge}=$ sample proportion used to estimate the second population proportion

$p_{1}=$ probability of the first population proportion

$p_{2}=$ probability of the second proportion

$\bar{p}=$ Weighted estimate of $p$

$\bar{q}=$ Weighted estimate of $q$

Also,

$\bar{p}=\frac{x_{1}+x_{2}}{n_{1}+n_{2}}$

$p_{1}=\frac{x_{1}}{n_{1}}$

$\bar{q}=1-\bar{p}$

$p_{2}^{\wedge}=\frac{x_{2}}{n_{2}}$

where:

$n_{1}$ : Sample size of the first group

$n_{2}$ : Sample size of the second group

This gives:

Test value $=$

observed value - expected value standard error

where:

Observed value $=\mathrm{p} 1^{\wedge}-\mathrm{p} 2^{\wedge}$,

Expected value $=\mathrm{p} 1-\mathrm{p} 2$, and

Standard error $=\sqrt{p q}\left(\frac{1}{n_{1}}+\frac{1}{n_{2}}\right)$

The test was carried out at confidence level (x) of .05 (as usually accepted for such analysis) and the critical values were +1.96 and -1.96 .

\subsection{Analysis Methodology}

\subsubsection{Direct-effect Sites ( $R / D$ and G/D Intersections)}

These sites were compared to no-effect sites ( $\mathrm{S} / \mathrm{N}$ and $\mathrm{J} / \mathrm{N}$ Intersection). Similar observation periods were compared as well as the average proportion of red light violators for all periods at each site. The results of the test of hypothesis on both proportions are presented in Tables 710.

\subsubsection{Indirect-Effect Sites (R/ID and G/ID Intersections)}

These sites were compared with no-effect sites ( $\mathrm{S} / \mathrm{N}$ and $\mathrm{J} / \mathrm{N}$ Intersections) to detect the second hypothesis of psychological effect of having red light cameras at the intersection even though there was no red light camera at the approach itself. The results of the test of hypothesis on both proportions are presented in Tables 11-14.

\subsubsection{Direct-effect Sites ( $R / D$ and $G / D$ Intersections)}

These sites were compared with the indirect-effect sites (same) to explore the difference between approaches of the same intersection where one had a red light camera and the other one did not have one. The results of the test of hypothesis on both proportions are presented in Tables 15 and 16.

\subsubsection{Same Type Sites}

They were compared to see if there is a significant difference concerning red light violators regardless of the presence of red light camera. The results of the test of hypothesis on both proportions are presented in Tables 17 and 18.

\section{Results \& Discussion}

\subsection{Selected Same Type Sites}

They were compared to detect if there was any inherent significant difference between the proportions of red light violators which might have been the result of unforeseen factors. The results obtained were:

1. No significant difference was obtained between proportions of red light violators at the direct effect sites at both $\mathrm{R} / \mathrm{D}$ and $\mathrm{G} / \mathrm{D}$ Intersections as presented in Table 17.

2. No significant difference was found between both controlled sites ( $\mathrm{S} / \mathrm{N}$ and $\mathrm{J} / \mathrm{N}$ Intersection) as shown in Table 18.

\subsection{Comparison between Direct-Effect Sites (Type I) and No-Effect Sites (Type III)}

The results of this comparison were:

1. Proportion of red light violators at R/D Site (Type I) was significantly less than the proportion of red light violators at the S/N-Controlled site (Type III). The reduction was more than eighty percent. The red light cameras had a significant effect on reducing red light violations. Going through the periods of the day, the significant impact was noticed during morning and afternoon peak hours. It seems that driver behavior during peak hours tends to be more irritated as they rush to reach their work or drop their children at schools or when coming back from work so they take chances in violating red light. In this case, it seems 
Table 7. A summary of the Z-test of proportions of red light violators at R/D (Type I) and S/N/ (Type III) intersections

\begin{tabular}{lccccc}
\multicolumn{1}{c}{ Site } & $\begin{array}{c}\text { Morning } \\
\text { peak }\end{array}$ & $\begin{array}{c}\text { Morning } \\
\text { off-peak }\end{array}$ & $\begin{array}{c}\text { Afternoon } \\
\text { peak }\end{array}$ & $\begin{array}{c}\text { Night } \\
\text { time }\end{array}$ & All day \\
Regency type I & 0.32175 & 0.525394 & 0.092937 & 0.556328 & 0.331633 \\
Sheraton type III & 3.421053 & 1.724138 & 1.432665 & 1.068376 & 1.877023 \\
Z-value & -5.63995 & -1.78999 & -3.35874 & -0.99387 & -5.89109 \\
Significance & yes & no & yes & no & yes
\end{tabular}

Table 8. A summary of the Z-test of proportions of red light violators at R/D (Type I) and J/N (Type III) intersections

\begin{tabular}{lccccc}
\multicolumn{1}{c}{ Site } & $\begin{array}{c}\text { Morning } \\
\text { peak }\end{array}$ & $\begin{array}{c}\text { Morning off - } \\
\text { peak }\end{array}$ & $\begin{array}{c}\text { Afternoon } \\
\text { peak }\end{array}$ & $\begin{array}{c}\text { Night } \\
\text { time }\end{array}$ & All day \\
Regency type I & 0.32175 & 0.525394 & 0.092937 & 0.556328 & 0.331633 \\
Jufair type III & 2.307692 & 1.935484 & 0.529101 & 2.006689 & 1.752922 \\
Z-value & -4.65618 & -2.18005 & -1.70548 & -2.13707 & -5.89911 \\
Significance & yes & yes & no & yes & yes
\end{tabular}

Table 9. A summary of the Z-test of proportions of red light violators at G/D (Type I) and S/N (Type III) intersections

\begin{tabular}{lccccc}
\multicolumn{1}{c}{ Site } & $\begin{array}{c}\text { Morning } \\
\text { peak }\end{array}$ & $\begin{array}{c}\text { Morning off- } \\
\text { peak }\end{array}$ & $\begin{array}{c}\text { Afternoon } \\
\text { peak }\end{array}$ & Night time & All day \\
Gulf type I & 0.09311 & 1.495327 & 0.740741 & N/A & 0.604933 \\
Sheraton type III & 3.421053 & 1.724138 & 1.432665 & N/A & 1.877023 \\
Z-value & -5.70961 & -0.26598 & -1.00637 & N/A & -3.59715 \\
Significance & yes & yes & no & N/A & yes
\end{tabular}

N/A: not available

Table 10. A summary of the Z-test of proportions of red light violators at G/D (Type I) and J/N (Type III) intersections

\begin{tabular}{lccccc}
\multicolumn{1}{c}{ Site } & $\begin{array}{c}\text { Morning } \\
\text { peak }\end{array}$ & $\begin{array}{c}\text { Morning off- } \\
\text { peak }\end{array}$ & $\begin{array}{c}\text { Afternoon } \\
\text { peak }\end{array}$ & Night time & All day \\
Gulf type I & 0.09311 & 1.495327 & 0.740741 & N/A & 0.604933 \\
Jufair type III & 2.307692 & 1.935484 & 0.529101 & N/A & 1.752922 \\
Z-value & -4.6938 & -0.57182 & 0.444033 & N/A & -3.53396 \\
Significance & yes & no & no & N/A & yes
\end{tabular}

N/A: not available

Table 11. A summary of the Z-test of proportions of red light violators at R/ID (Type II) and S/N (Type III) intersections

\begin{tabular}{lccccc}
\multicolumn{1}{c}{ Site } & $\begin{array}{c}\text { Morning } \\
\text { peak }\end{array}$ & $\begin{array}{c}\text { Morning off- } \\
\text { peak }\end{array}$ & $\begin{array}{c}\text { Afternoon } \\
\text { peak }\end{array}$ & Night time & All day \\
Regency type II & 0.670641 & 2.018349 & 0.869565 & 1.301115 & 1.066667 \\
Sheraton type III & 3.421053 & 1.724138 & 1.432665 & 1.068376 & 1.877023 \\
Z-value & -4.2145 & 0.313759 & -0.80204 & 0.339155 & -2.2489 \\
Significance & yes & no & no & no & yes
\end{tabular}

Table 12. A summary of the Z-test of proportions of red light violators at R/ID (Type II) and J/N (Type III) intersections

\begin{tabular}{lccccc}
\multicolumn{1}{c}{ Site } & $\begin{array}{c}\text { Morning } \\
\text { peak }\end{array}$ & $\begin{array}{c}\text { Morning } \\
\text { off-peak }\end{array}$ & $\begin{array}{c}\text { Afternoon } \\
\text { peak }\end{array}$ & Night time & All day \\
Regency type II & 0.670641 & 2.018349 & 0.869565 & 1.301115 & 1.066667 \\
Jufair type III & 2.307692 & 1.935484 & 0.529101 & 2.006689 & 1.752922 \\
Z-value & -3.32515 & 0.101445 & 0.68973 & -0.79104 & -2.15364 \\
Significance & yes & no & no & no & yes
\end{tabular}


Table 13. A summary of the Z-test of proportions of red light violators at G/ID (Type II) and S/N (Type III) intersections

\begin{tabular}{lccccc}
\multicolumn{1}{c}{ Site } & $\begin{array}{c}\text { Morning } \\
\text { peak }\end{array}$ & $\begin{array}{c}\text { Morning } \\
\text { off-peak }\end{array}$ & $\begin{array}{c}\text { Afternoon } \\
\text { peak }\end{array}$ & Night time & All day \\
Gulf type II & 0.809717 & 0.807754 & 1.808067 & 3.583062 & 1.405241 \\
Sheraton type III & 3.421053 & 1.724138 & 1.432665 & 1.068376 & 1.877023 \\
Z-value & -3.5187 & -1.28973 & 0.447022 & 2.407941 & -1.18064 \\
Significance & yes & no & no & yes & no
\end{tabular}

Table 14. A summary of the Z-test of proportions of red light violators at G/ID (Type II) and J/N (Type III) intersections

\begin{tabular}{lccccc}
\multicolumn{1}{c}{ Site } & $\begin{array}{c}\text { Morning } \\
\text { peak }\end{array}$ & $\begin{array}{c}\text { Morning } \\
\text { off-peak }\end{array}$ & $\begin{array}{c}\text { Afternoon } \\
\text { peak }\end{array}$ & Night time & All day \\
Gulf type II & 0.809717 & 0.807754 & 1.808067 & 3.583062 & 1.405241 \\
Jufair type III & 2.307692 & 1.935484 & 0.529101 & 2.006689 & 1.752922 \\
Z-value & -2.65796 & -1.70617 & 2.054346 & 1.174946 & -0.99032 \\
Significance & yes & no & yes & no & no
\end{tabular}

Table 15. A summary of the Z-test of proportions of red light violators at R/D (Type I) and R/ID (Type II) intersections

\begin{tabular}{lccccc}
\multicolumn{1}{c}{ Site } & $\begin{array}{c}\text { Morning } \\
\text { peak }\end{array}$ & $\begin{array}{c}\text { Morning off- } \\
\text { peak }\end{array}$ & $\begin{array}{c}\text { Afternoon } \\
\text { peak }\end{array}$ & Night time & All day \\
Regency type I & 0.32175 & 0.525394 & 0.092937 & 0.556328 & 0.331633 \\
Regency type II & 0.670641 & 2.018349 & 0.869565 & 1.301115 & 1.066667 \\
Z-value & -1.34983 & -2.23996 & -2.49844 & -1.40281 & -3.76983 \\
Significance & no & yes & yes & no & yes
\end{tabular}

Table 16. A summary of the Z-test of proportions of red light violators at G/D (Type I) and G/ID (Type II) intersections

\begin{tabular}{lccccc}
\multicolumn{1}{c}{ Site } & Morning peak & $\begin{array}{c}\text { Morning off- } \\
\text { peak }\end{array}$ & $\begin{array}{c}\text { Afternoon } \\
\text { peak }\end{array}$ & Night time & All day \\
Gulf type I & 0.09311 & 1.495327 & 0.740741 & N/A & 0.604933 \\
Gulf type II & 0.809717 & 0.807754 & 1.808067 & N/A & 1.405241 \\
Z-value & -2.46598 & 1.103645 & -1.624 & N/A & -2.70644 \\
Significance & yes & no & no & N/A & yes
\end{tabular}

N/A: not available

Table 17. A summary of the Z-test of proportions of red light violators at R/D (Type I) and G/D (Type I) intersections

\begin{tabular}{lccccc}
\multicolumn{1}{c}{ Site } & $\begin{array}{c}\text { Morning } \\
\text { peak }\end{array}$ & $\begin{array}{c}\text { Morning off }- \\
\text { peak }\end{array}$ & $\begin{array}{c}\text { Afternoon } \\
\text { peak }\end{array}$ & Night time & All day \\
Regency type I & 0.32175 & 0.525394 & 0.092937 & N/A & 0.331633 \\
Gulf type I & 0.09311 & 1.495327 & 0.740741 & N/A & 0.604933 \\
Z-value & 1.207262 & -1.62447 & -2.21174 & N/A & -1.559 \\
Significance & no & no & no & N/A & no
\end{tabular}

N/A: not available

Table 18. A summary of the Z-test of proportions of red light violators at $\mathrm{S} / \mathrm{N}$ (Type III) and J/N (Type III) intersections

\begin{tabular}{lccccc}
\multicolumn{1}{c}{ Site } & Morning peak & $\begin{array}{c}\text { Morning off } \\
\text { peak }\end{array}$ & $\begin{array}{c}\text { Afternoon } \\
\text { peak }\end{array}$ & Night time & All day \\
Sheraton type III & 3.421053 & 1.724138 & 1.432665 & 1.068376 & 1.877023 \\
Jufair type III & 2.307692 & 1.935484 & 0.529101 & 2.006689 & 1.752922 \\
Z-value & 1.137912 & -0.23357 & 1.427326 & -1.06597 & 0.285958 \\
Significance & no & no & no & no & no
\end{tabular}


that the red light camera affected their behavior and resulted in less red light violators at the R/D intersection compared to the $\mathrm{S} / \mathrm{N}$ Intersection.

During other periods of the day, there were no significant differences even though the proportion of red light violators at the $\mathrm{R} / \mathrm{D}$ site was always less than the $\mathrm{S} / \mathrm{N}$ site throughout the day. So the effect of red light camera still prevailed but not significantly. Generally, the effect of red light cameras was significant through out the whole day.

2. A significant reduction in red light violators was observed at the R/D site (Type I) compared to the $\mathrm{J} / \mathrm{N}$ site (one without redlight cameras). The reduction was around eighty percent (Table 8 ). The significant reduction was observed during all times of the day except in the afternoon peak. The proportion of red light violators was less at the R/D site compared to the $\mathrm{J} / \mathrm{N}$ site in the afternoon peak but not significantly.

3. Proportions of red light violators during all times of the day were statistically more at the $\mathrm{S} / \mathrm{N}$ site (without red light cameras) compared to the G/D site (Type I), except for the afternoon peak where the difference was not significant. The reduction was about two-thirds.

4. Throughout the times of the day the difference between the proportions of red light violators between the G/D site and the $\mathrm{J} / \mathrm{N}$ site was not significant, except for the morning peak hour. The sum of the proportion of red light violators at the G/D site was two thirds less than the Juffair site (Table 10). During the time of the day, the red light violators at the G/D site were less than the $\mathrm{J} / \mathrm{N}$ site, except during the afternoon peak when the opposite occurred but again it was not significant.

\subsection{Comparison Between Direct-Effect Sites (Type I) and Indirect-Effect Sites (Type II)}

1. At the R/ID Intersection, the approach with red light cameras (Type I) showed two-thirds less red light violators than the other approach at the same intersection without red light cameras (Type II). All results were significant. Through times of the day morning off-peak and afternoon peak showed significant results (Table 15).

2. Generally, at the G/D and G/ID Intersection the proportion of red light violators at the approach with red light cameras had less red light violators (reduced to half) than the other approach within the same intersection without red light cameras (Type II). The difference was statistically significant as shown in Table 16. During morning off-peak period, the red light violators were less in Type II approach compared to Type I approach. Except for the morning peak, the other periods showed a similar pattern but all of them were insignificant. It seems that the direct presence of red light cameras has more effect than the indirect effect of red light cameras.

\subsection{Comparison Between Direct-Effect Sites (Type II) and No-Effect Sites (Type III).}

The comparison was carried out to test the extended effect of the presence of red light cameras at one approach on the observed proportion of red light violators at other approaches within the same intersection.

1. Throughout the day the proportion of red light violators at the controlled site (S/N Intersection) was higher by about 25\% than the proportion at Type II (R/ID). The results were significant. During the times of the day, the pattern was inconsistent and showed almost no significance as presented in Table 11.

2. Analysis results had the same pattern similar to that of the previous case at both $\mathrm{R} / \mathrm{ID}$ and $\mathrm{J} / \mathrm{N}$ intersections with a reduction of about $40 \%$. However, there was no significant impact of the times of the day on the results (Table 12).

3. The total proportion of the observed red light violators was less at the G/ID site compared to the S/N site, but not significantly as presented in Table 13. During different times of the day, the proportion of red light violators fluctuated, with no consistent behavior as it was in the case of R/ID site (Type II).

4. Over all, the proportion of red light violators at the $\mathrm{J} / \mathrm{N}$ site was $20 \%$ higher than the G/ID site but the differences were not significant as presented in Table 14. During different times of the day, no consistent pattern was observed regarding the red light violators and most of the results were not significant.

Generally, the presence of the redlight cameras in the intersection would have an extended effect to approaches other than the particular approach that has red light cameras, but with less significant influence.

\section{Conclusions}

Conclusions derived from this study include:

1. In general the study shows that red light cameras (direct-effect) installed at signalized intersections have an effect on reducing the proportion of red light violators compared to approaches in signalized intersections without a red light camera at all (no-effect). The reduction in the proportion of red light violators averaged between $66 \%$ and $84 \%$ compared to red light violators at signalized intersections without red light cameras. These results confirm earlier findings (Ruby and Hobeika, 2003; Retting et al, 1999 a; Fleck and Smith, 1999). The significant reductions in the proportion of red light violators occurred during most of the day, and especially during peak hours.

2. It seems that the effect of the presence of red light cameras at an approach within a signalized intersection influenced other approaches in the same intersection (indirect-effect) in terms of reducing the proportion of red light violators, which agreed with other studies (Retting et al. 1999 b). The amount of reduction was less compared to the direct-effect approaches. The results showed less significant reductions in red light violations compared both to direct-effect 
approaches, as well as to no-effect approaches.

3. Red light cameras have an impact on reducing the proportion of red light violators. The size of this impact varies during the times of the day. Most of the effect could be observed during the peak hours. The effect of the presence of red light cameras might extend to approaches within the same intersection. The results were not firmly conclusive, but the indicators were observed and recorded.

\section{Recommendations}

The following recommendations are warranted of this:

1. It is strongly recommended to proceed with the installation of red light camera devices and to upgrade them with the latest technologies as to ensure better performance and reliability of the system.

2. These results might be reflecting the ambiguity of the local situation. Red light cameras are a relatively new technology. Drivers are not properly educated about this new system. Moreover, it is still not included in the training program of new drivers. No significant awareness campaigns were launched either before or after installing the new system.

3. It is believed that more reductions in the number of red light violators would be achieved if more attention is given to education and awareness campaigns. As a result, red light cameras will be more effective in reducing red light violators.

\section{Scope of Future Work}

Additional future work items include:

1. More sites should be evaluated once new red light cameras are installed to extend our data base. This might lead to more conclusive results.

2. The results of this study should be correlated with traffic safety records at the same intersections.

3. An economic analysis should be made to justify the installation of red light cameras.

\section{References}

Baughman, C., 2002, "A Data Collection Method for Red Light Running," Proceeding of the International Conference on Applications of Advanced Technologies in Transportation Engineering, pp. 207214, Cambridge, MA, USA.

Blakey, L. T., 2003, "Red-Light Cameras: Effective Enforcement Measures for Intersection Safety," ITE Journal (Institute of Transport Engineer), Vol. 73(3), pp. 34-36, 43, USA.

Bluman, A. G., 1992, "Elementary Statistics," Wm. C. Brown Publisher (WCB).

Chen, G., Wilson, J., Meeckle, W. and Cooper, P., 2002,
"Evaluation of Photo Radar Program in British Columbia," Accident Analysis \& Prevention, Vol. 32(4).

Datta, T. K., Schattler K. and Datta, S., 2000, "Red Light Violations and Crashes at Urban Intersections," Transportation Research Record, No. 1734, pp. 52-58, Washington, D.C., USA.

Fleck, J. L. and Smith, B. B., 1999, "Can We Make RedLight Runners Stop? Red Light Photo Enforcement in San Francisco, California," Transportation Research Record, No. 1693, pp. 46-49, Washington, D.C., USA.

Harbord, B. and Jones, J., 1996, "Variable Speed Limit Enforcement - the M25 Controlled Motorway Pilot Scheme," Proceedings of the 1997 IEE Colloquium on Camera Enforcement of Traffic Regulations, London, UK.

Kea, M. D., Povey, L. J. and Firth, W. J., 2002, "Further Results from a Trial Comparing a Hidden Speed Camera Programme with Visible Camera Operation," Accident Analysis \& Prevention Periodical, Vol. 34(6).

Keenan, D. J., 2001, "Measuring the Effect of Speed Enforcement Cameras on Traffic Speed Violations," Institute of Transport Studies (ITS) - University of Leeds, UK

Lawson, S. D., Morris, H. T., Handy, R. W. and Howard, A. C., 1992, "Red Light and Surveillance Cameras Policy Issues Related to Accident Reduction and Enforcement," IEE Conference Publication, No. 355, pp. 38-42, London, UK.

Magee, A. R., 1000, "A Review of the Potential Benefits of Speed Control Using ATT Applications," Institute of Transport Studies (ITS)-University of Leeds, UK.

Miller, J. S., 2003, "Two Methodological Considerations for Evaluating Safety Impacts of Photo-Red Enforcement," ITE Journal (Institute of Transportation Engineers), Vol. 73(1), pp. 20-24, USA.

Ponter, B. E. and Derry, T., 1996, "A Nation Wide Survey of Self-reported Red Light Running: Measuring Prevalence, Predictors \& Perceived Consequences," Accident Analysis \& Prevention: Vol. 33(6).

Retting, R. A. and Williams, A. F., 1996, "Characteristics of Red Light Violators: Results of a Field Investigation," J. of Safety Research, Vol. 27(1), pp. 9-15, USA.

Retting, R. A., Williams, A. F., Farmer, C. M. and Feldman, A. F., 1999, "Evaluation of Red Light Camera Enforcement in Fairfax, Virginia, USA," ITE Journal (Institute of Transportation Engineers), Vol. 69(8), pp. 30-34, USA.

Retting, R.A., Williams, A. F., Farmer, C. M. and Feldman, A. F., 1999, "Evaluation of Red Light Camera Enforcement in Oxnard, California," Accident Analysis and Prevention, Vol. 31(3), pp. 169-174, USA.

Ruby, D.E. and Hobeika, A.G., 2003, "Assessment of Red 
Light Running Cameras in Fairfax Country, Virginia," Transportation Quarterly, Vol. 57(3), pp. 33-48, USA.

Salter, R. J., 1988, "Highway Traffic Analysis and Design," Macmillan Education, UK.

Schattler, K. L., Datta, T. K. and Hill, C. L., 2003, "Change and Clearance Interval Design on Red Light Running and Late Exits," Transportation Research Record, No. 1856, 03-2943, pp. 193-201, Washington, D.C., USA.
Tarawneh, T. M., Singh, V. A. and McCoy, P. T., 1999, "Investigation of Effectiveness of Media Advertising and Police Enforcement in Reducing Red Light Violations," Transportation Research Record, No. 1693, pp. 37-45, Washington, D.C., USA.

Wissinger, L. M., Hummer, J. E. and Milazzo, J. S., 2000, "Using Focus Groups to Investigate Issues of Red Light Running," Transportation Research Record, No. 1734, pp. 38-45, Washington, D.C., USA. 